\title{
MEMORABLE MESSAGES FROM FATHERS TO CHILDREN THROUGH SPORTS: PERSPECTICES FROM SONS AND DAUGHTERS
}

\author{
A Thesis \\ Presented to \\ The Graduate Faculty of The University of Akron
}

In Partial Fulfillment

of the Requirements for the Degree

Master of Arts

Shawn Starcher

August, 2013 


\title{
MEMORABLE MESSAGES FROM FATHERS TO CHILDREN THROUGH SPORTS: PERSPECTICES FROM SONS AND DAUGHTERS
}

\author{
Shawn Starcher
}

Approved:

Accepted:

Advisor

Dean of the College

Dr. Elizabeth Graham

Dr. Chand Midha

Faculty Reader

Dr. Heather Walter

Dean of the Graduate School

Dr. George R. Newkome

Faculty Reader

Date

Dr. Kathleen Stansberry

School Director

Dr. Elizabeth Graham 


\begin{abstract}
This study investigates memorable messages that sons and daughters report receiving from their fathers or step-fathers while actively or passively participating within the environment of sports together. The premise was to examine the messages that fathers use with children and how this may relate to the relationship satisfaction of the sons and daughters later in life. Also of interest, is the comparison of messages that fathers share with sons and daughters. Findings from the study indicate that fathers share messages with sons and daughters centered on five supra-types including Effort, Quality Traits, Emphasis on Physical Skills/Performance, Attention on Others and Have Fun. A chisquare analysis was used to determine that fathers share similar messages with sons and daughters, while ANOVA test results point to a significant relationship between certain types of memorable messages offered by fathers when compared with the relationship satisfaction reported by sons and daughters later in life.
\end{abstract}

Keywords: Family Communication; Memorable Messages; Socialization, FatherDaughter Communication; Father-Son Communication 


\section{ACKNOWLEDGEMENTS}

It would not have been possible to write this thesis without the help and support of the kind people around me, to only some of whom it is possible to give particular mention here. Above all, I would like to thank my wife Lori for her personal support, unending encouragement and great patience at all times. I would like to also thank my daughter Marysa for her encouragement and inspiration. I would not have been able to complete this thesis without their support.

Secondly, I would like to express my sincere gratitude to my advisor Dr. Elizabeth Graham for her continuous support of my study and research, combined with her patience, motivation, enthusiasm, and immense knowledge. Here guidance helped me in all the time of research and writing of this thesis. I could not have imagined having a better advisor and mentor for my studies.

Besides my advisor, I would like to thank the rest of my thesis committee: Dr. Heather Walter and Dr. Kathleen Stansberry for their encouragement, insightful comments, time and effort in helping me complete this thesis. I would also like to thank Dr. Yang Lin for his early assistance with the foundations of my thesis and continued support and encouragement throughout.

Last but not least, I would like to thank the faculty and secretaries in the School of Communication that were always willing to help in any capacity. You make me proud to say that I am a graduate from The University of Akron based on your commitment to education. 


\section{TABLE OF CONTENTS}

\section{Page}

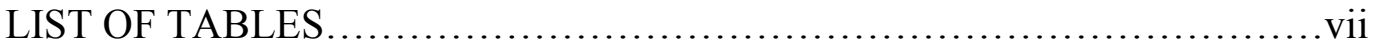

\section{CHAPTER}

I. INTRODUCTION ...........................................

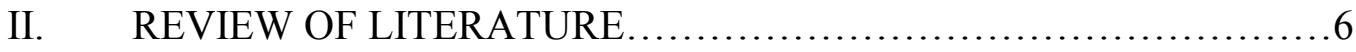

Socialization.............................................6

Language Socialization Theory.............................10

Memorable Messages.........................................10

Relationship Satisfaction...................................13

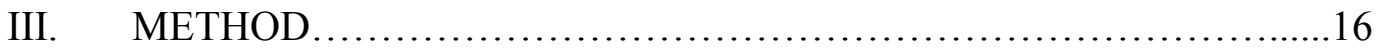

Participants.............................................16

Procedures................................................ 17

Revised Quality Marriage Index...............................18

Coding.....................................................19

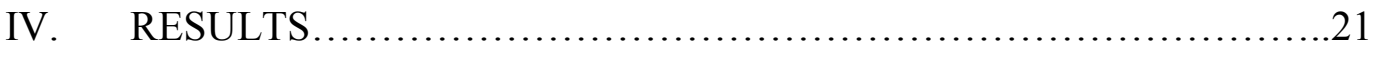

Memorable Message Type Descriptions........................21

Similarities and Differences of Memorable Messages...............27

Relationship Satisfaction with Memorable Messages...............29 
V. DISCUSSION .................................................. 32

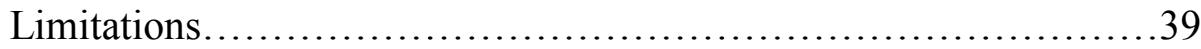

Future Implications......................................40

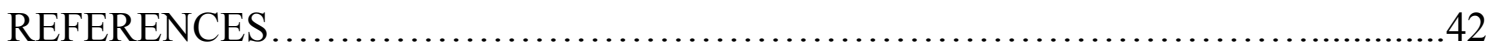

APPENDICES.........................................................48

APPENDIX A: SURVEY INSTRUMENT ..........................49

APPENDIX B: CONTENT ANALYSIS CODEBOOK..................55

APPENDIX C: UNIVERSITY OF AKRON IRB APPROVAL...........56 


\section{LIST OF TABLES}

Table $\quad$ Page

$1 \quad$ Frequencies and Examples of Memorable Messages Types...................22

2 Chi-square: Memorable Messages by Gender...........................................28

3 ANOVA Summary: Relationship Satisfaction with Memorable Messages....30

4 ANOVA Table: Tukey HSD Post Hoc Test Results..........................31 


\section{CHAPTER I}

\section{INTRODUCTION}

Sports have always had a place in society. From the humble beginnings of early civilization to the current multi-billion dollar industry, sports have created its own niche in nearly every culture. This notion is even more prevalent in the United States where children spend a large amount of time centered on sports when compared to other cultures (Larson \& Verma, 1999). It is not uncommon for a child to play multiple sports during the same season or to finish one practice session only to be shuttled by parents or caregivers to another session for a different sport. It is also not uncommon for families to gather around the television on Thanksgiving Day to watch football after enjoying a large holiday meal together. Sports are customary in our society and have an important impact on families as well. While some parents see sports as a frivolous activity, other parents see sporting activities (whether participating or observing/listening) as a way of socializing their children to important values and skills (Kremer-Sadlik \& Kim, 2007). Socialization refers to the process of social interaction through which children develop, extend and modify their conceptions of who they are and how they relate to the social world around them (Coakley, 1986). 
Tabula rasa is the Latin term for the English phrase blank slate. Seventeenthcentury English philosopher John Locke (1690/1959) stated that as newborns, children enter the world in a state of being that can be understood as tabula rasa. He also believed that in the course of experiencing their environments after birth, caregivers significantly influence a child's nature. Even before birth, fetuses are aware of their mother's tone of voice to the extent that "prenatal auditory experiences can influence postnatal auditory preferences" (DeCasper \& Spence, 1986, p. 133). These findings emphasize the importance of parents, grandparents or caregivers in the process of socialization. Sports provide an ample opportunity for the socialization process, and more specifically, sports-related contexts "act as important loci for the socialization of children" to the parents' values and beliefs (Kremer-Sadlik \& Kim, 2007, p. 37).

Ochs and Schieffelin (1994) take the concept of socialization even further and state that "the primary concern of caregivers is to ensure that their children are able to display and understand behaviors appropriate to social situations" (p. 470). They posit that one of the major means of accomplishing this goal is through language. The distinct ways that parents use language and express messages can have a lasting impression on children. Memorable messages are one of those distinctive methods used by parents or caregivers that have a profound effect on children later in life.

According to the seminal study by Knapp, Stohl and Reardon (1981), memorable messages are defined as brief statements received at a relatively early age, readily recalled for a long period of time afterward, and perceived to have influenced a person's life. There is an important parallel between memorable messages and socialization as both are received in the early stages of life (and throughout life as well) and tend to 
influence or shape a person's perspective of the world. These messages might be stories that parents pass on to children, often with the intention of teaching values or providing life lessons (Stone, 2004). According to Koenig Kellas (2010), “(t)hese lessons might be embraced or rejected; but whether positive or negative, the content of the parent-child communication is often memorable and may have a lasting impression on children" (p. 459). While memorable messages have been examined in several environments, limited research has examined the messages that fathers communicate to children and how these messages may affect children later in life.

Sports provide a compelling environment for memorable messages, especially within the dynamic of the parent-child interaction. As stated previously, children in the United States spend a large amount of time in sporting activities when compared to children in other cultures (Larson \& Verma, 1999). The increased amount of time spent on sports may have created an inverse effect on the amount of time spent between parents and children. Research has shown that over the last forty-five years, the amount of time children spend with their parents has gone down by ten to twenty hours per week (Meeker, 2007). While there is no conclusive evidence to point out why there is such a drastic reduction in the amount of time children spend with their parents, it does add to the significance of studying the interactions between parents and children in an environment where children spend a considerable amount of time. Previous research has found that the American culture is centered on sports and thus parent-child interactions may be more prevalent within this context. These interactions may occur on the drive home after a game or while watching a game together. Regardless, this setting provides ample time for parents and children to discuss what happened or could have happened on 
the field of play, while also allowing the parents to socialize children to their values and beliefs.

Traditionally, fathers have been thought to be the primary influence on children in regard to sports. Fathers generally tend to be the most active and passive participant in sports, when compared with the mother. Previous research has also found that fathers are typically responsible for providing the "scaffolding for physical play and culturally appropriate gender roles while mothers model verbal play and flexibility to individual needs and differences" with their children (Socha \& Yingling, 2010, p. 26). These forms of communication from fathers can happen in many different forms, but usually occur when attempting to correct and/or critique the athletic performance of children or while teaching children the framework for how to act appropriately while participating in sports. Sports columnist and author Mike Lupica (2009) stated that some of the best and most informative moments of his life were spent watching and interacting with his father regarding sports, while also adding that sitting with his daughter and having her ask questions about the game was one of the greatest joys of his life. Of course, not all communication is positive. Fathers may also offer communication that may be negative in nature as well.

Whether through active or passive participation, sports provide a rich environment for father-child communication and will be the primary setting in this study. The inclusion of passive participation is important as most of the previous research has emphasized active participation in sports as the most common venue for socialization to occur (Coakley, 1986; Fredicks \& Eccles, 2005; Green \& Chalip, 1997; Kanters, Bocarro \& Casper, 2008), however, passive participation including observing and/or listening to 
sporting events together where neither the father or child is active or talking about previous sporting experiences can also be influential in shaping children's lives and socializing them to understand their parent's attitudes, beliefs and values. Through the lens of language socialization theory, memorable messages from fathers to their sons and daughters while actively or passively participating in sports, and later recalled as adults, will be examined in this investigation. Attention will also be focused on message differences and/or similarities communicated from the father to sons and daughters. Furthermore, a closer examination will focus on whether certain memorable messages may relate to the relationship satisfaction between children and fathers. 


\section{CHAPTER II}

\section{REVIEW OF LITERATURE}

\section{Socialization}

Schieffelin and Ochs (1986) posit that socialization begins at the very beginning of life at the first moment of social contact. Childhood socialization occurs most often through parent-child interactions that revolve around exploring, discovering and judging what is appropriate at any given moment. Children learn about their worlds and their place in the world through language and the different forms of communication used in family interactions (Peterson \& Rollins, 1987). Goodman (1985) views socialization as a negotiated reality and states that there are three sub-processes within this socialization perspective including learning, social interaction, and communication. According to this current study, the negotiated reality of the lessons and values obtained are learned within the social interaction and communication of the father-child relationship through memorable messages. These memorable messages received as children and recalled as adults that are featured in the context of sports will be examined in this study, as well as how those messages may relate to the relationship satisfaction between children and fathers.

Early research focusing on parents and children concentrate on the mother as the primary parent, while the father's role was largely overlooked entirely or "relegated to a minor background position" (Evans, 1979, p. 1-2). Fagot, Rodgers and Leinbach (2002) 
found that much of the information concerning the role of fathers has come from mothers and the information that we do know is "biased toward well-educated fathers" (p. 74), while primarily focusing on interactions in infancy and early childhood. Current research found that this trend has continued, albeit for different reasons, as fathers are either reluctant research participants or because scholars have often worked under the assumption that mothers are more responsible than fathers for child socialization (Kirkman, Rosenthal, \& Feldman, 2002). This current study will shift the focus to the father-child relationship.

The research featuring fathers and their children has found that fathers have a large impact on the development of children including, but not limited to, an increased sense of well-being, cognitive development and social competence (Day \& Lamb, 2004; Lamb, 2002; Lewis \& Lamb, 2003; Martin, Ryan \& Brooks-Gunn, 2007; Pleck, 1997). Recent research has also found that children tend to have better academic achievement when fathers offer the provision of warmth and control (Levine Coley, 2008). The National Fatherhood Initiative (2010) has examined multiple studies and found that children living without their father are two to three times more likely to experience some form of educational, health, emotional or behavioral problems when compared with their peers living with parents that includes either biological or adoptive fathers.

With the increased awareness of the effect fathers have on children, research has found that many men are striving to be a more integral part of their children's lives, especially as compared to their own fathers (Morman \& Floyd, 2002; Pruett, 2000). The societal expectations for fathers are changing as well as "fathers are expected to be more involved with their children today more than ever before" (Anderson \& Sabatelli, 2011, 
p. 225). Sports, whether in active or passive participation, can foster and facilitate the opportunity for fathers to be an important part of their child's life. Sports, in essence, could act as the conduit that allows fathers to talk about life and communicate their beliefs, values and expectations to their children.

For many families, sports are an integral part of the family schedule. According to Kremer-Sadlik and Kim (2007), sport activities comprise roughly $24 \%$ of a families' total time spent on activities, which was second only to school-related work and afterschool programs. Studies have shown that participation in sports has a positive effect on youth development, social adjustment, and educational outcomes (Eccles, Barber, Stone, $\&$ Hunt, 2003). There have been many studies examining these perspectives under the premise of socialization through sports (Coakley, 1986; Fredicks \& Eccles, 2005; Green \& Chalip, 1997; Kanters, et al., 2008; Kremer-Sadlik \& Kim, 2007) but none of them have focused on the concepts of socialization through memorable messages received from fathers and recalled later in life by adult sons and daughters.

Traditionally, it might have been thought that fathers could socialize their sons primarily through messages while playing or watching sports together as there were fewer opportunities for girls to participate in sports as children. The passing of Title IX in 1972 changed the sporting landscape and in turn, may have opened the door for fathers to share similar messages with their daughters. Title IX, which requires gender equity for boys and girls in every educational program that receives federal funding (including sports), offers the chance for girls to have the same opportunity to participate in sports as boys. According to a study completed by the Women's Sports Foundation ("Women play sports," 2011), only 294,000 girls competed in high school sports the year before 
Title IX was passed into law, whereas in 2011 that figure rose to 3.1 million girls. These findings provide clear evidence that more girls are playing sports today than forty years ago, and thus the conversations between fathers and daughters might have evolved with those changes as well. This current study will offer some insight into this phenomenon.

The dynamics and nuances of the father-son relationship are different from those involved in the mother-son, mother-daughter and father-daughter relationship (Beatty \& Dobos, 1992). Children typically receive different socialization messages from mothers and fathers (Medved, Brogan, McClanahan, Morris \& Shepherd, 2006). As newborns, boys and girls are handled differently and may be provided with sex-appropriate toys, while other studies have focused on how children learn about masculine and feminine gender roles and physical appearance from their parents as well (Galvin, Bylund \& Brommel, 2012). Children learn how to distinguish feminine or masculine behavior from parents through comments made about weight, appearance, and dress (Wood, 2011). Gender-based socialization may also include socialization into a particular family role and what it means to be a son or daughter (Morman \& Floyd, 2006). Studies have shown that the "gender-based communication directives you received as a child come into play when you have your own family system and try to communicate effectively" (Galvin et al., 2012, p. 153). While socialization by gender has been studied extensively, no studies have focused on the realm of sports when comparing and contrasting memorable messages recalled later in life, especially those messages shared between father-sons and father-daughters. 


\section{Language Socialization Theory}

Language socialization theory states that through language acquisition and language use, children are socialized to sociocultural knowledge, norms, and values (Ochs \& Schieffelin, 1994). Parents play an active role in the socialization process. By examining the lessons learned through father-child interactions, we can explore the tools and strategies used by fathers for socializing their children through memorable messages. Socialization may be demonstrated in the form of passive or active participation in interaction (Kremer-Sadlik \& Kim, 2007). Once again, this is an important differentiation as most of the previous research focused primarily on active participation of sports as the most common tool for socialization (Coakley, 1986; Fredicks \& Eccles, 2005; Green \& Chalip, 1997; Kanters et al., 2008). The inclusion of passive participation, including observing and/or listening to sports or talking about sporting experiences, allows for a wider range of interactions centered on sports that can also be influential in shaping children's lives and socializing them to understand their parent's attitudes, beliefs, and values. Next, memorable messages communicated to sons and daughters through active or passive participation in the sports environment will be discussed.

\section{Memorable Messages}

Memorable messages are defined as brief statements received at a relatively early age, readily recalled for a long period afterwards, and perceived to have influence on one's life (Knapp et al., 1981). Memorable messages provide a conduit for communicating social knowledge across multiple generations and could serve as a guide to current thinking and behavior (Medved \& Graham, 2006). Through these interactions 
with offspring, parents provide "developmental scaffolding in the form of metaphors, stories, proverbs or questions" (Waldron, Goman, Piemonte, Kloeber \& Danaher, 2012, p. 3). These messages are typically internalized (Knapp et. al, 1981) and continue to influence people's lives long after they are received (Stohl, 1986). Stohl (1986) also posits that $55 \%$ of messages include some kind of prescriptive markers that indicate behaviors that should or should not be acted upon and also argues that these messages provide a "rich source of information about ourselves and our ways of communicating and socializing" (p. 232).

Memorable messages vary depending on the sex of the child and which parent is communicating the message. Historically, studies have found that fathers typically talk more with sons than daughters (Lamb, 1978), which may mean that fathers may be more inclined to share a larger number of memorable messages with sons compared to daughters. Block (1976) also found that fathers interact with sons and daughters in very different ways, while mothers react to sons and daughters in similar ways. This research suggests that sons and daughters may receive different messages from fathers. Johnson (1975) advanced the notion further and posits that fathers encourage sons to take on more independent styles of behavior, while daughters are encouraged to seek more help and to be more dependent on others. While this research may be dated, there are no studies that have disputed this research.

The passing of Title IX, along with the increased time that families spend on sporting activities, may create a different perspective when comparing the messages that fathers offer to sons and daughters. Sports were typically considered more masculine in nature. The research suggests that fathers might offer sons memorable messages while 
participating in a sporting environment, but messages from fathers to daughters may not be as prevalent. This current study hopes to offer clarity on this subject and provide insight into the memorable messages that fathers offer to both sons and daughters within the realm of sports.

Previous studies focused on family communication have found that mothers, rather than fathers, have primarily been the sources of memorable messages (Holladay, 2006; Keating, Shaw \& Smith, 2012). These findings have been especially dominant when focusing on the messages conveyed between mothers and daughters when discussing relational obligations such as leaving the workforce after having children or the roles that work and family should play in life as young adults begin to enter the work force (Medved \& Graham, 2006). As mentioned previously, studies have also confirmed that daughters receive different socialization messages from their fathers about how to balance work and family, including encouragement to choose a career that will allow them to handle family responsibilities, to rationally plan the order of key life events and to stop working when raising young children (Medved \& Graham, 2006).

Other studies of memorable messages have focused on how organizations may integrate new employees into the workplace culture (Stohl, 1986), how young adults navigate college life (Kranstuber, Carr, \& Hosek, 2011), how women handle and manage the expectations of motherhood (Heisler \& Butler Ellis, 2008) and how on-campus mentors share messages with first-generation college students (Wang, 2012). While the aforementioned studies have focused on memorable messages, no known studies have focused on how these messages might relate to the relationship satisfaction between the person offering the message and the person receiving the message. The content of these 
messages may not only be memorable for years to come, but they may also affect the relationship satisfaction between the individuals' years after the message is communicated. This current study will examine relationship satisfaction in conjunction with memorable messages in order to provide further insight into the father-son and father-daughter relationship.

\section{Relationship Satisfaction}

Stafford and Bayer (1993) state that one of the main reasons for socialization research is to provide a "prescription for how parents should interact with children to bring about optimal development" (p. 89). Memorable messages can be the conduit for socialization and are "often transmitted in family settings from parent to child and have a lasting impact beyond the parent-child interaction" (Koenig Kellas, 2010, p. 461). These messages may not only socialize the child to the values, beliefs and attitudes of the parent, but may also affect the overall relationship satisfaction between the parent and the child. Pearson (1989) stated that satisfaction is the primary criterion for evaluating the quality of family communication. The way that sons and daughters interpret messages from fathers may provide insight into their present-day relationship satisfaction with their fathers.

There are two types of satisfaction that have been examined in communication research, relational and communication (Punyanunt-Carter, 2002). Relational satisfaction is defined as the feelings toward another and the quality of the relationship (Dainton, Stafford, \& Canary, 1994). Communication is an essential component to relational satisfaction (Dindia, 1994). In this current study, memorable messages may impart relational satisfaction. Studies have found that families that display more supportive, 
agreeable and positive statements tend to have higher levels of relational satisfaction (Richards, 1989). Beatty and Dobos (1992) discovered that "fathers who are concerned about their sons' satisfaction with the relationship should probably focus on messages that illustrate supportive-interest; criticism and sarcasm should be avoided or reduced" (p. 282). These same messages may have similar effects on the father-daughter relationship as well, but no research has been completed at this time to confirm or deny this possibility. Beatty and Dobos (1992) stated that "any stimulus that fulfills needs, produces rewards or positive reinforcement, or confirms one's ideal self-image, produces satisfaction" (p. 163). This definition may apply to messages that offer support and are positive in nature, but what happens when the message is negative and denies the recipient's ideal self-image? Not all memorable messages from fathers are positive and this may have some effect on the relationship satisfaction of sons and daughters. Further research is necessary to offer some insight into this phenomenon.

At this point, there is no known research that has focused on the importance of the father-child interaction within the context of sports and how this might serve as a socializing agent in shaping children's perspective of the world. Furthermore, there is no known research that has focused on memorable messages received as a child and how those messages might relate to the relationship satisfaction between fathers and children later in life. This study hopes to provide some clarity by answering the following research questions:

RQ1 - What types of memorable messages do sons and daughters report receiving from their fathers while actively or passively participating in sports? 
RQ2 - Is there a difference between the type of memorable messages that sons and daughters report receiving from their fathers while actively or passively participating in sports?

RQ3 - Is there an association between the type of memorable messages that sons and daughters report receiving from their fathers while actively or passively participating in sports and their current satisfaction with their relationship with their father? 


\section{CHAPTER III}

\section{METHOD}

\section{Participants}

Participants in this study consisted of 65 volunteers (30 men and 35 women) that ranged in age from 18-66 $(M=35.6, S D=8.972)$. Eleven participants were between the ages of 18-29, while the majority of the participants (42) were between the ages of 30-39. Of the remaining participants, 8 were between the age range of $40-49$ and 4 were between the ages of 50-66. Fifty-eight of those participants (89.2\%) identified themselves as Caucasian/Non-Hispanic, 5 (7.7\%) participants identified themselves as African American/Non-Hispanic and $2(3.1 \%)$ listed themselves as other. The majority of the participants played sports as children or adolescents $(84.6 \%)$, while most of the participants $(70.8 \%)$ currently have children of their own. The participants were asked to provide memorable messages received from their father or step-father while actively or passively participating in sports together. To qualify to participate, participants must have been at least 18 years of age, have had the memory of a father or step-father in their early life, and once had an in interest in participating and/or observing/listening to sporting events. Participants for this study were asked whether they would share the message that their father shared with them and $86.1 \%$ of participants said that there was a very good chance that they would share this or a similar message with their child. 


\section{Procedures}

After obtaining human subjects approval from the University of Akron Institutional Review Board, participants were recruited through the author's Facebook and Twitter accounts and then through a snowball sampling method. The participants were directed to an on-line survey instrument using Qualtrics and were asked to provide demographic information including age, ethnicity and whether they played sports during childhood. In addition to demographic questions, participants were requested to respond to several open-ended and close-ended questions about memorable messages received as children from a father or step-father as well as a revised measure of the Quality Marriage Index (QMI), which is a measure of relationship satisfaction that was modified for use in this study.

Participants were asked to write up to two memorable messages that they could recall their father or step-father offering them while actively or passively participating in sports together that had a lasting impression on them in some way. Active participation is defined as playing sports together or the child was an active participant and the father may be in the stands or on the sideline, while passive participation would include observing and /or listening to sporting events or talking about previous sporting experiences together (i.e., watching sports on television, going to sporting events together, listening to a sporting event on the radio, etc.). Fathers and step-fathers were specifically chosen over "father figures" in order to shed light on the messages that fathers or step-fathers provide to their children, which has been lacking in previous research on parent-child socialization and memorable messages. 
The instructions to participants provided four examples to illustrate what is meant by a memorable message and to help participants remember what messages might have been conveyed from their fathers or step-fathers. Depending on the interpretation of the messages, two of the messages may be seen as positive messages, while two of the messages may be seen as negative. Examples provided included the positive message "my father used to tell me that I need to be a good sport win or lose," and the negative message "my father used to tell me that winning is all that matters, even if I have to cheat in order to win." Participants were provided explicit instructions that these examples should not influence or limit their own message reports. Participants were also instructed that remembering these memorable messages did not mean that they actually took their father's advice.

Revised Quality Marriage Index

Relationship quality will be assessed using a revised version of the Quality Marriage Index (QMI). The QMI is a six-item inventory that assesses marital quality and was developed in 1983 by Robert Norton. While the QMI was initially designed to assess marital quality, studies have found that the measure also successfully assesses nonmarital relationships (Baxter \& Bullis, 1986). The wording of the items was changed to gauge the quality of the relationship satisfaction of the respondent with their father or step-father. As an example, the first item of the QMI states "We have a good marriage" (Norton, 1983). The revised item for this survey asked the question, "Me and my father have/had a good relationship." The participant was directed to identify the degree of agreement with each of the five items on a Likert scale ranging from 1 (very strong disagreement) to 7 (very strong agreement) and one last item which assesses the overall 
degree of happiness in the relationship between the father and child on a scale ranging from 1 (very strong disagreement) to 10 (very strong agreement). The cumulative total of all six questions was added together to determine the overall relationship satisfaction between sons and daughters with fathers and step-fathers. Higher scores represent a higher level of relationship satisfaction for the child with their father or step-father. The Cronbach alpha for the revised QMI in the current study was .98 $(M=37.91, S D=11.18)$, which is consistent with prior research using a revised versions of the QMI between that reported alpha reliabilities between .90-.94 (Merolla, 2008; Villella \& Ryan, 2010).

\section{Coding}

All of the memorable messages collected were examined together as one data set. The messages were not marked as being received from a male or female participant to avoid any coding bias. A content analysis, which Neuendorf (2002) defines as a "summarizing, quantitative analysis of messages" (p. 10) was completed and is appropriate in this study when analyzing the memorable messages that sons and daughters recollect receiving from their father or step-father in the environment of sports.

In the initial coding phase, messages were analyzed by the researcher through the lens of the language socialization theory and were grouped into categories based on recurrence of similar message meanings or repetition of key words, phrases or sentences until all the messages were placed into a category (Owen, 1984). The categories were then examined a second time by the researcher to refine the categories into a coherent set of types. The data was revisited a third time by the researcher to determine larger, more encompassing themes and subtypes. 
Once the initial coding phase was completed, a final coding scheme (See Appendix B) was created in order to train two independent coders to examine the data. During the training process, two independent coders were provided with the final coding scheme that featured the supra-types and subtypes of messages along with the definition for each supra-type and key words/phrases to look for when coding. Following training, the two coders each coded a random sample of $25 \%(n=27)$ of the memorable message data. Each memorable message was assigned one dominant supra-type. Intercoder reliability was calculated using Cohen's Kappa at $\mathrm{K}=.89$, which indicates very good intercoder reliability.

The next step focused on analyzing the differences between the messages received from fathers by sons and daughters while actively or passively participating in sports. A comparison was made between the themes offered by male and female participants to determine if fathers offered different messages to sons and daughters. A chi-square analysis was conducted to resolve RQ2.

The final research question tested the association between the memorable messages that sons and daughters report receiving from their fathers while actively or passively participating in sports and how that relates to their current satisfaction in their relationship with their father or step-father. A one-way Analysis of Variance (ANOVA) test was used to analyze RQ3. 


\section{CHAPTER IV}

\section{RESULTS}

\section{Memorable Message Type Descriptions}

Research question one (RQ1) examined the memorable messages that sons and daughters report receiving from their father or step-father while actively or passively participating in sports. Sons and daughters reported 108 memorable messages in roughly equal numbers (sons provided 56 and daughters offered 52). The findings of the coding process revealed the existence of five supra-types of memorable messages, including Effort, Quality traits, Emphasis on physical skills/performance, Attention on others and Have fun. Four of the supra-types were comprised of subtypes. Frequencies and examples are presented in Table 1, followed by specific descriptions for each type of message. 
Table 1 Frequencies and Examples of Memorable Messages

\begin{tabular}{|c|c|c|c|}
\hline \multicolumn{2}{|r|}{ Supra-type and Subtype Categories } & Frequency & Example \\
\hline \multirow{5}{*}{1.} & Effort & $n=47$ & \\
\hline & Subtype: Try your best & $n=19$ & $\begin{array}{l}\text { "My dad always told me to do the } \\
\text { best you can and that's al that } \\
\text { matters. Whether you finish first } \\
\text { or last, you will feel good about } \\
\text { the results as long as you tried as } \\
\text { hard as you can." }\end{array}$ \\
\hline & Subtype: Never give up & $n=12$ & $\begin{array}{l}\text { "Once you start something you } \\
\text { don't quit. You don't have to do it } \\
\text { again next year/season, but you } \\
\text { don't quit." }\end{array}$ \\
\hline & Subtype: Give $100 \%$ & $n=9$ & $\begin{array}{l}\text { "The main thing he did say is to } \\
\text { give } 100 \% \text { no matter what you } \\
\text { attempt because you can do } \\
\text { anything if you work hard at it." }\end{array}$ \\
\hline & Subtype: Practice is important & $n=7$ & $\begin{array}{l}\text { "My dad used to always tell me to } \\
\text { put forth my best effort at every } \\
\text { practice. Practice wasn't a time to } \\
\text { goof off. What I put in on } \\
\text { practice is what I would get on } \\
\text { game day." }\end{array}$ \\
\hline \multirow{4}{*}{2.} & Quality Traits & $n=27$ & \\
\hline & Subtype: Good sport & $n=14$ & $\begin{array}{l}\text { "Be a good sport. I didn't } \\
\text { understand sportsmanship much at } \\
\text { the time but listened to my } \\
\text { father." }\end{array}$ \\
\hline & Subtype: No cheating & $n=6$ & $\begin{array}{l}\text { "Cheaters never win and winners } \\
\text { never cheat." }\end{array}$ \\
\hline & Subtype: Loyalty to others & $n=7$ & $\begin{array}{l}\text { "Be loyal, support your team. } \\
\text { Support your teammates and } \\
\text { where you came from." }\end{array}$ \\
\hline \multirow{3}{*}{3.} & Emphasis on physical skills/performance & $n=16$ & \\
\hline & Subtype: Phsyical skills & $n=10$ & $\begin{array}{l}\text { "My father used to encourage me } \\
\text { to run and stay in top shape for } \\
\text { stamina." }\end{array}$ \\
\hline & $\begin{array}{l}\text { Subtype: Winning/performance is } \\
\text { everything }\end{array}$ & $n=6$ & $\begin{array}{l}\text { "Winning is everything. Second } \\
\text { place is the first loser." }\end{array}$ \\
\hline \multirow{3}{*}{4.} & Attention on others & $n=9$ & \\
\hline & Subtype: Professional athletes & $n=5$ & $\begin{array}{l}\text { "Professional athletes are not } \\
\text { heroes. They are not doing what } \\
\text { they do for the fans." }\end{array}$ \\
\hline & Subtype: Importance of team & $n=4$ & $\begin{array}{l}\text { "Give it your all, but remember } \\
\text { you are a part of a team and it's } \\
\text { not all up to just you." }\end{array}$ \\
\hline 5. & Have fun & $n=9$ & $\begin{array}{l}\text { "Doesn't matter if you win or lose } \\
\text { as long as you have fun." }\end{array}$ \\
\hline
\end{tabular}


Effort. These messages reflected reinforcement by the fathers to the sons and daughters to never give up and for the child to maximize their effort in order to achieve their full potential on the practice field or during games. Of the 108 memorable messages reported across the sample, the most frequently occurring type $(n=47)$ included messages about the amount of effort expected by the father from sons and daughters. Four subtypes emerged within this category.

Messages in the first subtype, Try your best, emphasized maximizing the child's abilities and typically included the phrases "try your best," "do your best," and/or "work hard." The second subtype, Never give up, focused on the idea that regardless of the situation that the child should never give up. This subtype usually included the statements "never quit," "it's never over," "finish" and "stick with it."

The third subtype, labeled Give 100\%, stressed the importance of the children to provide maximum effort in every situation and typically included the phrases "give $100 \%$ " or "give it your all."

Practice is important, which was the fourth subtype, emphasized the high amount of effort needed during practice in order to increase the child's performance during the actual games. There is a focus from the father or step-father to make sure that the proper foundation is laid before the game is actually played, with a specific focus on the effort and work needed outside of the normal game setting. Most of the memorable messages featured the word "practice" and usually referenced that "one has to practice to be good" or "practice makes perfect." Many of the participants mentioned that these types of 
memorable messages transferred over to other areas of their lives and, in essence, they were socialized to always put forth their best effort in all of their endeavors.

Quality traits. These messages, which were the second most frequently occurring type of message $(n=27)$, focused on the father or step-father conveying the idea for the child not to cheat, play by the rules, show good sportsmanship and remain loyal to others. There were three subtypes within this supra-type: Good sport, No cheating, and Loyalty to others. With Quality traits memorable messages, the children were being socialized to act in the manner that the father or step-father deemed appropriate. The father or stepfather wanted to make sure that the sons and daughters understood that exemplifying the traits integrity, character, and loyalty were important and should be present in interactions with others on and off the field of play.

The No cheating subtype included the key words and phrases such as "don't cheat" and "play fair," while the Good sport subtype featured the key words and phrases "gracious," "good sport," "sportsmanship," “respect rules," "honor," “never fight," "integrity" and "act like you should."

The third and final subtype, Loyalty to others, emphasized the importance for sons and daughters to remain loyal to their team, teammates and their surrounding area. The messages also were implied by the presence of the fathers or step-fathers as well. One participant mentioned that she could not remember a specific message, but did offer that her father was always there to help and she took that to mean that her father was always there to support her and was very loyal to her and her needs. Other participants mentioned how they were told to "support their team," whether that meant their teammates or their local sports teams, and to root for them at all times. These messages 
typically included the words "loyal," "being there," and "support." Once again, these are also messages that could translate to other areas of the sons and daughters lives, but were shared and exposed within the environment of sports.

Emphasis on physical skills/performance. These types of messages $(n=16)$ emphasized the need for the child to improve an area of their skill set and/or technique or stressing that winning should be the ultimate goal at all times. There were two subtypes within this supra-type: Physical skills and Winning/performance is everything.

The Physical skills messages ranged from "keep your eye on the ball," which is important in the game of baseball or football, to the emphasis on "sports isn't for everyone," indicating that the child may not have the requisite skills to continue playing this (or any) sport. In the latter situation, the implied message was that another venue may be the best way for the child to succeed in life. Most of the key words or phrases mentioned some part of the body or body motion to focus on, while also mentioning "technique" and/or "skills."

The second subtype, Winning/performance is everything, were very specific in conveying the message that the child should win or perform at a high level by any means necessary. There was typically a negative connotation for those children that did not win or perform well. One participant recalled his father telling him to "not come home if I didn't score a touchdown," while another offered the message that his father told him to "win at any cost" and to "exploit the weaknesses of your opponent." These messages were very different from the other messages received as they were not supportive for the child or the team and placed the emphasis on the outcome of the game and/or the child performing well by any means necessary. These messages seemed to directly oppose the 
other types of messages mentioned as the emphasis is to motivate the child to succeed at all costs, even if it meant sacrificing the child's integrity/character/loyalty, having fun or supporting their team.

Attention on others. This specific type of memorable message $(n=9)$ conveyed by the fathers or step-fathers focused on the value of others outside of the child directly. The fathers typically focused on some aspect of professional athletes in regards to their skill, value or conduct off the field or that the team is more important than the individual. There were two subtypes within this supra-type: Professional athletes and Importance of team.

The first subtype, Professional athletes, featured messages from fathers that mentioned professional athletes in some capacity. There was a specific focus on accentuating what the athletes might do on the field of play, while also making sure that the child understood that they were "real people" as well. In most cases the child should emulate the skills that the player used on the field of play, but not necessarily how they act in real life. Messages also offered the ideals that athletes "get paid too much" and that "they will break your heart" if you get too attached to the athletes. The fathers seemed to want to draw a line of how far the child should take their adoration for the professional team or athlete.

The second subtype of the Attention on others supra-type messages, Importance of team, shifted the emphasis from the child and placed it directly on the team and its importance over the individual. There were few of these messages, but their importance cannot be overstated. In an individualistic American culture, this message would seem to run contrary to popular belief. The majority of the other memorable messages focused on 
the child improving themselves (mentally and physically), having fun or performing well, which made the Importance of team messages stand out even more. The overriding meaning for Importance of team messages typified that "every position is important," "there is no 'I' in team," and the "team is more important" than the individual. The Importance of team messages socialized the sons and daughters to understand that the child should focus outward on individuals and events outside of themselves instead of focusing inward. This message is important as children typically focus on themselves and their needs without considering the effects that their behaviors or actions may have on others.

Have fun. These messages were very clear in meaning and stood alone when compared with the other messages. Due to the clarity and simplicity of this message, these types of messages did not have any subtypes. Have fun messages $(n=9)$ focused on the father making sure that the child understood to have fun, first and foremost. These were messages in which fathers encouraged children to forget about winning and losing and typically involved words and phrases that included "have fun," "enjoy yourself," "joy," "fun," and "it's not always about winning." The children in these messages were socialized to enjoy themselves, while de-emphasizing the need for improving physical skills or the need for winning.

\section{Similarities and Differences of Memorable Messages}

Research question number two (RQ2) shifted the focus to the difference between the memorable messages that sons and daughters report receiving from their fathers while actively or passively participating in sports. There were 65 total participants involved with this study (30 men and 35 women) and 43 of those participants offered multiple 
messages. Some of the memorable messages for the participants that provided multiple messages fell across multiple supra-types. In order to avoid any confusion when analyzing the messages, only the first reported memorable message for each participant was calculated when analyzing RQ2. These messages were seen as the most important messages as they were reported first. Each son and daughter was coded according to their initially reported supra-type theme (Effort, Quality Traits, Emphasis on Physical Skills/Performance, Attention on Others and Have Fun) and that theme was calculated against the gender of the participant. This allowed for a simple comparison of the messages based on the total amount of messages offered by each gender. Table 2 provides the frequencies and breakdown of memorable messages by gender.

Table 2 Frequencies and Breakdown of Memorable Messages by Gender

\begin{tabular}{|l|l|c|c|c|c|}
\hline \multicolumn{2}{|c|}{ Supra-type and Subtype Categories } & $\begin{array}{c}\text { Male } \\
\text { Expected }\end{array}$ & $\begin{array}{c}\text { Male } \\
\text { Observed }\end{array}$ & $\begin{array}{c}\text { Female } \\
\text { Expected }\end{array}$ & $\begin{array}{c}\text { Female } \\
\text { Observed }\end{array}$ \\
\hline 1 & Effort & 15.7 & 16 & 18.3 & 18 \\
\hline 2 & Quality Traits & 4.6 & 6 & 5.4 & 4 \\
\hline 3 & Attention on Others & 4.6 & 5 & 5.4 & 5 \\
\hline 4 & $\begin{array}{l}\text { Emphasis on Physical } \\
\text { Skills/Performance }\end{array}$ & 1.4 & 2 & 1.6 & 1 \\
\hline 5 & Have Fun Total Messages & 3.7 & 1 & 4.3 & 7 \\
\hline \multicolumn{2}{|l|}{} & 30 & & 35 \\
\hline
\end{tabular}

A chi-square was conducted to assess whether sons and daughters report receiving different memorable messages from their fathers while actively or passively participating in sports. The result for the chi-square test was not significant: $\chi^{2}(4, N=65)=4.996, \mathrm{p}$ 
$<.288$. While the test results indicate that there were no significant differences in the memorable messages received by sons and daughters, there is interest in discovering that there are similarities in the messages received by sons and daughters, which will be discussed in the following chapter.

Relationship Satisfaction with Memorable Messages

Research question number three (RQ3) focused on whether there were any significant differences between memorable messages that sons and daughters report receiving from their fathers while actively or passively participating in sports and their current satisfaction in their relationship with their father. Since there were no significant differences found in the memorable messages reported by sons and daughters as discovered in RQ2, the memorable messages for sons and daughters were combined to form one data set to provide the resolution for RQ3. As mentioned previously, some of the messages for the participants that provided multiple messages fell across multiple supra-types. In order to avoid any confusion when analyzing the messages in comparison with the relationship satisfaction score with the father or step-father, only the first reported memorable message for each participant was calculated when analyzing RQ3. Each son and daughter was coded according to their initially reported supra-type theme (Effort, Quality Traits, Emphasis on Physical Skills/Performance, Attention on Others and Have Fun) and that theme was calculated against their reported relationship satisfaction score with their father or step-father.

A one-way Analysis of Variance (ANOVA) was calculated using the supra-type memorable message theme as the independent variable and the relationship satisfaction score using the revised QMI as the dependent variable. Each of the participants was 
coded into only one of the memorable message themes. A significant difference was noted at the $\mathrm{p}<.003$ level: $F(4,60)=4.93, \mathrm{p}=.002$. See Table 3 for full results.

Table 3 ANOVA Summary - Relationship Satisfaction with Memorable Messages

\begin{tabular}{|l|c|c|c|c|}
\hline \multicolumn{1}{|c|}{ Source } & Sum of Squares & $d f$ & Mean Square & \\
\hline Between Groups & 1976.86 & 4 & 494.22 & $\mathrm{~F}=4.93$ \\
\hline Within Groups & 6018.58 & 60 & 100.31 & \\
\hline Total & 7995.45 & 64 & & \\
\hline
\end{tabular}

A Tukey HSD post hoc indicated that there was a significant difference between the relationship satisfaction of sons and daughters reporting memorable messages with the supra-type Effort $(M=41.324, S D=1.718)$ and sons and daughters reporting memorable messages with the supra-type Emphasis on Physical Skills/Performance ( $M=26, S D=3.167$ ), as well as sons and daughters reporting memorable messages with the supra-type Have Fun $(M=41.125, S D=3.541)$ and sons and daughters reporting memorable messages with the supra-type Emphasis on Physical Skills/Performance $(M=26, S D=3.167)$. In essence, the sons and daughters reported having a significantly higher relationship satisfaction score with their father or step-father that offered memorable messages focused on Effort and Have Fun, while having a significantly lower relationship satisfaction score with messages that placed an Emphasis on Physical Skills/Performance. See Table 4 for complete results. 
Table 4 Tukey HSD Post Hoc Test Results

\begin{tabular}{|c|c|c|c|c|c|}
\hline & Supra-type Category & $\begin{array}{c}\text { Supra-type Category } \\
\text { Compared Against }\end{array}$ & $\begin{array}{c}\text { Mean } \\
\text { Difference }\end{array}$ & $\begin{array}{c}\text { Standard } \\
\text { Error }\end{array}$ & Significance \\
\hline \multirow{4}{*}{1.} & \multirow{4}{*}{ Effort } & Quality Traits & 6.12 & 3.603 & .442 \\
\hline & & $\begin{array}{l}\text { Emphasis on Physical } \\
\text { Skills/Peformance }\end{array}$ & $15.32 *$ & 3.603 & .001 \\
\hline & & Attention on Others & 1.99 & 6.032 & .997 \\
\hline & & Have Fun & 0.2 & 3.936 & 1.000 \\
\hline \multirow{4}{*}{2.} & \multirow{4}{*}{ Quality Traits } & Effort & -6.12 & 3.603 & .442 \\
\hline & & $\begin{array}{l}\text { Emphasis on Physical } \\
\text { Skills/Peformance }\end{array}$ & 9.20 & 4.479 & .254 \\
\hline & & Attention on Others & -4.13 & 6.593 & .970 \\
\hline & & Have Fun & -5.93 & 4.751 & .724 \\
\hline \multirow{4}{*}{3.} & \multirow{4}{*}{$\begin{array}{l}\text { Emphasis on Physical } \\
\text { Skills/Performance }\end{array}$} & Effort & $-15.32 *$ & 3.603 & .001 \\
\hline & & Quality Traits & -9.20 & 4.479 & .254 \\
\hline & & Attention on Others & -13.33 & 6.593 & .268 \\
\hline & & Have Fun & $-15.13^{*}$ & 4.751 & .019 \\
\hline \multirow{4}{*}{4.} & \multirow{4}{*}{ Attention on Others } & Effort & -1.99 & 6.032 & .997 \\
\hline & & Quality Traits & 4.13 & 6.593 & .970 \\
\hline & & $\begin{array}{l}\text { Emphasis on Physical } \\
\text { Skills/Peformance }\end{array}$ & 13.33 & 6.593 & .268 \\
\hline & & Have Fun & -1.79 & 6.781 & .999 \\
\hline \multirow{4}{*}{5.} & \multirow{4}{*}{ Have Fun } & Effort & -.20 & 3.936 & 1.000 \\
\hline & & Quality Traits & 5.93 & 4.751 & .724 \\
\hline & & $\begin{array}{l}\text { Emphasis on Physical } \\
\text { Skills/Peformance }\end{array}$ & $15.13^{*}$ & 4.751 & .019 \\
\hline & & Attention on Others & 1.79 & 6.781 & .999 \\
\hline
\end{tabular}




\section{CHAPTER V}

\section{DISCUSSION}

This study investigated the memorable messages that sons and daughters recall receiving from their fathers while actively or passively participating in sports together. There was clear evidence that fathers use memorable messages through the environment of sports to socialize children in a variety ways. As mentioned previously, Coakley (1986) refers to socialization as the process of social interaction through which children develop, extend and modify their conceptions of who they are and how they relate to the social world around them. All of the messages mentioned by the participants offered some communication from their father in order to modify or change the perspective or behavior of the son or daughter. In essence, the context of sports provided fathers the opportunity to share these significant messages, while also allowing them to socialize their son or daughter.

While the messages shared within the context of sports apply directly to those environments centered on sports, the messages can also be applied in other environments as well, a sentiment often shared by the participants. One of the participants commented that their father shared their particular message with them because "it also applies to life," while also offering that their father inferred through a particular message that they should "take no shortcuts and do the right thing even though no one is watching." Another participant offered that his father advised him to never quit because the child had 
a history of quitting and that the message "resonates still today." These messages were important enough to transcend the playing field and had a lasting impression on the child that carried into adulthood and served to socialize the son or daughter.

Previous research found that mothers were typically responsible for socializing children (Kirkman, Rosenthal, \& Feldman, 2002), but this current study offers evidence that fathers are involved as well. Due to the traditionally masculine nature of sports, it could be thought that some fathers may feel more comfortable communicating with sons and daughters in this environment. If this is true, then fathers may have an environment where they can socialize their sons and daughters to their attitudes, beliefs and values. This is even more significant within the American culture, where sports centered activities are such a large part of family interactions. For this study, fathers were found to encourage their children to offer more effort and to never give up, while also advising them to be good sports and remain loyal to others. These are important values for children to learn and to adopt in order to become productive members of society and the environment of sports offers the context for those messages to be shared.

Earlier research also found that fathers typically talk more with sons than daughters (Lamb, 1978), which may mean that fathers may be more inclined to share a larger number of memorable messages with sons compared to daughters. The current study found that twenty-six of the thirty male participants $(87 \%)$ cited two memorable messages received from a father or step-father; while only seventeen of the thirty-five female participants (49\%) were able to recall two memorable messages. This could be happenstance that more male participants were able to recall two memorable messages, or it could provide more evidence that fathers shared more messages with sons than 
daughters. While Title IX may have allowed fathers to share more messages with daughters in the environment of sports, this study found that fathers may still be sharing more messages with sons. Future research is necessary to determine if Lamb's (1978) initial findings are still accurate.

As mentioned previously, socialization by gender has been studied extensively, but no known studies have focused on the realm of sports when comparing and contrasting memorable messages recalled later in life, especially those messages shared between father-son and father-daughter. Previous research (Block, 1976) found that fathers interact with sons and daughters in very different ways. The current study examined this phenomenon and results indicated that there were no significant differences found in the messages that fathers offer sons and daughters while actively or passively participating in sports. While these results are not statistically significant, perhaps there may be some important information to be gleaned from this discovery. The fact that fathers shared similar messages with their sons and daughters in this study requires future research. Earlier studies on memorable messages have shown that sons and daughters receive different memorable messages from their fathers. This current study may offer different results based on the environment and masculine nature of sports, but perhaps there may be a larger reason under the surface.

With the passing of Title IX in 1972, more girls are competing in sports today than in previous generations. Before the passing of Title IX, messages of socialization through sports would have been tailored for sons as most daughters would not have played sports. During this time frame, fathers that initially shared these messages were socialized themselves as children to raise their children with certain values, beliefs and 
attitudes of that time period and there may have been little need for messages of socialization tailored for daughters. After the passing of Title IX, fathers may not have adjusted their messages to adapt with the change. In essence, the fathers would have been socialized to share a certain type of message that would be very appropriate for sharing with a son. Without an alternative message for daughters, fathers continued to share the messages that they learned as children.

The concept of passing down similar messages from one generation to the next is very typical in maintaining family traditions and heritage. As mentioned previously, participants for this study were asked whether they would share the message that their father shared with them and $86.1 \%$ of participants said that there was a very good chance that they would share this or a similar message with their child. If that rationale holds true, perhaps fathers are passing down similar messages that they received as children, which may have been initially established for fathers to share with their sons and not daughters.

While the results show that there were no significant differences in the memorable messages recalled from sons and daughters later in life as adults, a closer examination into the subtypes of messages might offer a little more insight. Although it is a small sample within the larger data set, eight female participants recalled messages that focused on the message Have fun, while only one male participant reported receiving a similar message. There are many reasons that might have led to this disparity in recalled memorable messages by sons and daughters. One possible explanation centers on the idea that fathers or step-fathers realize that their daughter's chances to play professional sports is extremely small so they want them to have fun and enjoy themselves instead of 
focusing on improving their skills. It could be that fathers and step-fathers do not offer these messages to their sons as there is a remote chance that their son could have a future in professional sports in the National Football League (NFL), Major League Baseball (MLB), National Basketball Association (NBA), or National Hockey League (NHL), while daughters only have the opportunity to play professionally in the United States in the Women's National Basketball Association (WNBA).

There may be further evidence for this conclusion when examining the differences in the subtypes within the Attention on others supra-type. Once again, while it is a small sample of the entire data set, four male participants mentioned receiving memorable messages referring to professional athletes, while only one female participant received a similar message. This may be based on the assumption that fathers can offer messages to their sons that have hopes to play professionally, while daughters do not have a similar opportunity.

The importance of team subtype within the Attention on others supra-type may offer a similar conclusion. Three female participants received a message that focused on the importance of being part of a team, while only one male participant offered a similar message. Perhaps, some fathers with more traditional values may see a future where their daughter is relegated to handling maternal duties or becoming a caregiver and thus should not have any professional sports aspirations. In this case, daughters may be exposed to socialization messages from a father where they are expected to "do their part on the team at home" and that may include putting their career on hold while staying home with children or handling household matters and/or duties. As mentioned previously, Johnson (1975) found that fathers encourage sons to take on more independent styles of behavior, 
while daughters are encouraged to seek more help and to be more dependent on others. This study offers information consistent with this claim. Regardless of reason, future research is needed to examine this disparity.

Finally, this study sought to examine whether memorable messages shared from fathers with their sons and daughters through active or passive participation in sports might have any correlation with relationship satisfaction today between the son and daughter with their father. This portion of the study featured the most noteworthy results as there was a significant difference found in the reported relationship satisfaction scores of sons and daughters with fathers that offered messages based on Effort and Have fun, when compared to messages that featured an Emphasis on physical skills/performance.

There are many possible reasons for the results found that revealed differences between these types of memorable messages and relationship satisfaction, but it may boil down to the temperament of the father. The father that implements messages that seem more positive in nature such as having fun and/or improving their effort may be different from those of the father that uses messages centered on improving skills and/or winning at all costs. This falls in line with the findings from Beatty and Dobos (1992) that fathers that are concerned with relationship satisfaction of their child, should offer messages that focus on support instead of criticism.

When the father conveys the message that improved effort will increase successful results, the message implies that the child has the requisite skill set needed to succeed and the only variable that stands between the child and success is effort. When the father emphasizes messages that focus on physical skill improvement, they may be socializing the child to believe that the child does not currently have the requisite skills 
necessary to be successful and the child has to work on them in order for that to happen, if it will happen at all.

Likewise, messages that focus on winning at all costs offer a similar negative connotation that everything is to be sacrificed in order to win. The child may be socialized to believe that they have to win in order to please their father, which carries the expectation that their father cares more about winning than he may care about the child having fun. When the father offers the message to enjoy themselves and have fun, the child may interpret that message as their father cares about them having fun and in turn cares more about their feelings than the outcome of a sporting event.

It would be simple if it were that succinct, but there are probably many other variables that coincide with fathers that center their messages on physical skill improvement or winning at all cost. Perhaps, the father may want to see their son or daughter perform at a higher level than they did when they were a child and thus they push their child in a direction that emphasizes physical skill improvement or the idea of winning at all cost, at the expense of emphasizing effort or having fun. Regardless of the reasoning, it is important to understand that certain messages may have a positive or negative influence on the relationship satisfaction between the father and child. Future research will need to examine this phenomenon in greater detail.

In conclusion, as families spend a considerable amount of time in the sports environment, it is important to examine and analyze the way that fathers use this time to communicate with their sons and daughters. By examining memorable messages and the lessons learned from the sons and daughters perspective, one can have a better understanding of the tools and strategies used by fathers for socializing their children. 
This study has provided more insight into the messages fathers that share, especially in the environment of sports, which may have an impact on their children and could also have a direct correlation with the relationship between the individuals long after the message was offered. Although some of the findings of this study were significant, especially considering an environment where fathers seem to play a large role, there is still a lack of research focusing on the roles that fathers play in the socialization of their children. Further research needs to examine the importance of the father-son and fatherdaughter relationships as well as family communication within the environment of sports.

\section{Limitations}

Participants were recruited through the researcher's Facebook and Twitter accounts and through a snowball sampling method, which narrows the scope of the participants involved to friends and acquaintances of the researcher. The memorable messages were requested from the participants and had to be drawn from memory, which may have limited their ability to recall important memorable messages received as a child. Participants also may not have been able to remember significant messages at the time and the examples provided on the survey may have influenced the participants to recall similar experiences. The messages detailed from the participants may not offer a complete picture of all the messages that children may hear from fathers. The messages offered by the participants were not ranked for the significance of the message by the son or daughter. It was assumed for RQ3 that the most significant message was the first message listed by each participant. Future studies examining multiple messages will need to examine which messages were the most significant by the participant. 
The interactions between the father and the sons or daughters were not seen firsthand and cannot be validated by the researcher and could be skewed by interpretation or possibly remembered from overheard examples by friends. When coding the memorable messages, some messages contained multiple supra-type themes (i.e. "Never give up and always give 100\%). A decision was made beforehand to view each memorable message as one unit and not break the message into multiple separate messages. Future studies may look to break up the multiple messages contained within each singular recalled multiple message and examine each for its own significance or place the single message into multiple categories.

\section{Future Implications}

This study focused on the memorable messages in the father-child dyad through the environment of sports. Future studies may want to consider the implications of the memorable messages received from the mother since most of the previous research found that mothers typically have been found to provide most of the memorable messages in the parent-child relationship. Future studies may also include the memorable messages that were not directly conveyed from the father to the child and may have been passed on to the child through a coach or another friend. These messages may carry significant weight because the father shared a story about his child with another person.

Another study may also examine the different sports mentioned by the participants and see if there is any correlations or differences between the sports mentioned and if the messages varied by gender. Future researchers may also want to examine the difference between verbal or nonverbal messages passed along and whether that provided any additional lasting impression or significance for the child. Finally, 
researchers may want to examine whether messages were passed down from generation to generation and why these messages were so meaningful and enduring. 


\section{REFERENCES}

Anderson, S. A. \& Sabatelli, R. M. (2010). Family Interaction: A multigenerational developmental perspective ( $5^{\text {th }}$ ed.). Boston, MA: Allyn \& Bacon.

Baxter, L. A. \& Bullis, C. (1986). Turning points in developing romantic relationships. Human Communication Research, 12, 469-493.

Beatty, M. J. \& Dobos, J. A. (1992). Relationship between sons' perceptions of fathers' messages and satisfaction in adult son-father relationships. Southern Communication Journal, 57(4), 277-284.

Block, J. H. (1976). Issues, problems, and pitfalls in assessing sex differences: A critical review of "They psychology of sex differences." Merrill-Palmer Quarterly, 22, 283-308.

Caughlin, J. P., Koerner, A. F., Schrodt, P. \& Fitzpatrick, M. A. (2011). Interpersonal communication in family relationships. In Knapp, M. L. \& Daly, J. A. ( $4^{\text {th }}$ Ed.), The Sage Handbook of Interpersonal Communication (679-714). Thousand Oaks, CA: Sage Publications.

Chase, S. \& Whitbread, J. (1978). Daughters: From infancy to independence. Garden City, NY: Doubleday Publishing.

Coakley, J. (1986). Socialization and youth sports. In C. R. Rees \& A. W. Miracle (Eds.) Sport and social theory (pgs. 135-143). Champaign, IL: Human Kinetic Publishers

Cronbach, L. J. (1951). Coefficient alpha and the internal structure of tests. Psychometrika, 16, 297-334.

Dainton, M., Stafford, L., \& Canary, D. J. (1994). Maintenance strategies and physical affection as predictors of love, liking, and satisfaction in marriage. Communication Reports, 7, 88-97.

Day, R. \& Lamb, M. (2004). Conceptualizing and measuring father involvement: Pathways, problems, and progress. In R. Day \& M. Lamb (Eds.), Conceptualizing and measuring father involvement (pp. 1-16). Mahwah, NJ: Lawrence Erlbaum Associates. 
DeCasper, A. J. \& Spence, M. J., (1986), Prenatal maternal speech influences newborns' perceptions of speech sounds, Infant Behavior and Development, 9(2), 133-150.

Dindia, K. (1994). A multiphasic view of relationship maintenance strategies. In D. J. Canary \& L. Stafford (Eds.), Communication and relational maintenance (pp. 91112). San Diego, CA: Academic Press.

Eccles, J. S., Barber, B. L., Stone, M., \& Hunt, J. (2003). Extracurricular activities and adolescent development. Journal Of Social Issues, 59(4), 865. doi:10.1046/j.0022-4537.2003.00095.x

Evans, A. (1979). Daughters' perceptions of the effects of having lived with an emotionally distant father. (Doctoral dissertation, California School of Professional Psychology).

Fagot, B. I., Rodgers, C. S., \& Leinbach, M. D. (2002). Theories of gender socialization. In T. Heckes \& H. M. Trautner (Eds.), The Developmental Social Psychology of Gender 65-90. Mahwah, NJ: Lawrence Erlbaum Associates, Inc., Publishers

Fredericks, J.A. \& Eccles, J. S. (2005). Family socialization, gender, and sport motivation and involvement. Journal of Sport \& Exercise Psychology, 27, 3-31.

Galvin, K. M., Bylund, C. L. \& Brommel, B. J. (2012). Communication and Family Roles and Types ( $8^{\text {th }}$ ed.). Family Communication: Cohesion and Change (149177). New York, NY: Allyn \& Bacon

Goodman, N. (1985). Socialization I: A sociological overview. In H. A. Farberman \& R. S. Pesinbanayagam (Eds.) Foundations of interpretive sociology: Original essays in symbolic interaction (Supplement I) (pgs. 73-94). New York: JAI Press

Green, B. C. \& Chalip, L. (1997). Enduring involvement in youth soccer: The socialization of parent and child, Journal of Leisure Research, 29(1), 61-77.

Heisler, J. M., Butler Ellis, J. (2008). Motherhood and the construction of "mommy identity": Messages about motherhood and face negotiation. Communication quarterly, 56(4), 445-467.

Holladay, S. J. (2006). "Have fun while you can," "You're only as old as you feel," and "Don't ever get old!": An examination of memorable messages about aging. Journal of Communication, 52(4), 681-697.

Johnson, M. M. (1975). Fathers, mothers and sex typing. Sociological Inquiry, 45(1), 15-26. 
Kanters, M. A., Bocarro, J. \& Casper, J. (2008). Supported or pressured? An examination of agreement among parent's and children on parent's role in youth sports. Journal of Sport Behavior, 31(1), 64-80.

Keating, D. M., Shaw, A. S. \& Smith, S. W. (November, 2012). The intersection of family communication patterns and parental memorable messages about family communication. Unpublished paper presented at The National Communication Association Annual Meeting, Orlando, FL.

Kirkman, M., Rosenthal, D. A. \& Feldman, S. S. (2002). Talking to a tiger: Fathers reveal their difficulties in communication about sexuality with adolescents. New Directions for Child and Adolescent Development, 97, 57-74.

Knapp, M. L., Stohl, C., \& Reardon, K. K. (1981). "Memorable” messages. Journal of Communication, 31(4), 27-41.

Kranstuber, H., Carr, K. \& Hosek, A. M. (2012). "If you can dream it, you can achieve it." Parental memorable messages as indicators of college student success. Communication Education, 61(1), 44-66.

Kremer-Sadlik, L. \& Kim, J. (2007). Lessons from sports: Children's socialization to values through family interaction during sports activities. Discourse \& Society, 18(1), 35-52. doi: 10.1177/0957926507069456

Lamb, M. E. (1978). Qualitative aspects of mother and father infant attachments. Infant Behavior and Development, 1(1), 265-275.

Lamb, M. E. (2002). Infant-father attachments and their impact on child development. In C. Tamis-LeMonda and N. Cabrera (Eds.), Handbook of father involvement (pp. 93-119). Mahwah, NJ: Lawrence Erlbaum Associates.

Larson, R. W. \& Verma, S. (1999). How children and adolescents spend time across the world: Work, play and developmental opportunities. Psychological Bulletin, 125(6), 701-736.

Levine Coley, R. (2008). Children's socialization experiences and functioning in singlemother households: The importance of fathers and other men. Child Development, 69(1), 219-230.

Lewis, C. \& Lamb, M. (2003). Fathers' influences on children's development: The evidence from two-parent families. European Journal of Psychology of Education, 18(2), 211-228.

Locke, J. (1959). An essay concerning human understanding. New York, NY: Dover. (Original work published 1690). 
Lupica, M. (2009). Introduction. Fathers \& sons \& sports, vii-xv. New York, NY: ESPN Publishing.

Martin, A., Ryan, R. M., \& Brooks-Gunn, J. (2007). The joint influence of mother and father parenting on child cognitive outcomes at age 5. Early Childhood Research Quarterly, 22(4), 423-439.

Medved, C. E. \& Graham, E. E. (2006) Communicating contradictions:(Re) producing dialectical tensions through work, family, and balance: Socialization messages. Family communication sourcebook. Thousand Oaks, CA: SAGE Publications, Inc.

Medved, C. E., Brogan, S. M., McClanahan, A. M., Morris, J. F. \& Shepherd, G. J. (2006). Family and work socializing communication: Messages, gender and ideological implications. Journal of Family Communication, 6(3), 161-180.

Meeker, M. (2007). Strong fathers, strong daughters. New York, NY: Ballantine Books.

Merolla, A. J. (2008). Communicating forgiveness in friendships and dating relationships. Communication Studies, 59, 114-131.

Morman, M. T., \& Floyd, K. (2002). A “changing culture of fatherhood”; Effects on affectionate communication, closeness, and satisfaction in men's relationships with their fathers and their sons. Western Journal of Communication, 66, 395411.

Morman, M. T., \& Floyd, K. (2006). The good son: Men's perceptions of the characteristics of son-hood. In K. Floyd \& M. T. Morman (Eds.), Widening the family circle: New research on family communication (pp. 37-55). Thousand Oaks, CA: Sage.

Mueller, K. E. \& Powers, W. G. (1990). Parent-child sexual discussion: Perceived communicator style and subsequent behavior. Adolescence, 25(98), 469-482.

Neuendorf, K. A. (2002). The content analysis guidebook. Thousand Oaks, CA: Sage

Norton, R. (1983). Measuring marital quality: A quality look at the dependent variable. Journal of Marriage and the Family, 45, 141-151.

Ochs, E. \& Schieffelin, B. B. (1994). Language acquisition and socialization: Three developmental stories and their implications. In Ben G. Blount (Ed.), Language, Culture and Society (pgs. 470-511). Prospect Heights: Waveland. 
Owen, W. F. (1984). Interpretive themes in relational communication. Quarterly Journal of Speech, 70(1984), 274-287.

Pearson, J. C. (1989). Communication in the family: Seeking satisfaction in changing times. New York, NY: Harper \& Row

Peterson, G. W. \& Rollins, B. C. (1987). Parent-child socialization. In M. Sussman \& S. Steinmetz (Eds.) Handbook of marriage and the family (pgs. 471-499). New York: Plenum Press.

Pleck, J. (1997). Paternal involvement: Levels, sources, and consequences. In M. Lamb (Ed.), The role of the father in child development (pp. 66-103). New York: Wiley.

Pruett, K. (1987). The nurturing father. New-York: Warner.

Punyanunt-Carter, N. M. (2002). Using attachment theory to study satisfaction in fatherdaughter relationships. Human Communication, 10(2), 103-120.

Richards, D. D. (1989). The relationship between attributes of life and life judgments. Human Development, 32, 95-103.

Salute fatherhood. (2013). Retrieved from http://www.great-inspirationalquotes.com/father-quotes.html

Schieffelin, B. B. \& Ochs, E. (1986). Language socialization. Annual Review of Anthropology, 15, 163-191.

Socha, T. J. \& Yingling, J. (2010). Families communicating with children. Malden, MA: Polity Press.

Stafford, L. \& Bayer, C. L. (1993). Interaction between parents and children. Newbury Park, CA: Sage Publications.

Stafford, L. (2004). Communication competencies and sociocultural priorities of middle childhood. In A. Vangelisti ( $1^{\text {st }}$ Ed.), The Routledge Handbook of Family Communication, (p. 311-332). Psychology Press.

Stohl, C. (1986). The role of memorable messages in the process of organizational socialization. Communication Quarterly, 34(3), 231-249).

Stone, E. (2004). Black sheep and kissing cousins: How our family stories shape us. New Brunswick, NJ: Transaction.

The Issue of Father Absence. (2010). Retrieved February 6, 2013, from http://www.fatherhood.org/media 
Villella, S. A. \& Ryan, L., (2010). Broken up but not broken: Satisfaction, adjustment, and communication in post-dissolutional relationships. Unpublished paper presented at the annual meeting of the NCA $96^{\text {th }}$ Annual Convention, San Francisco, CA.

Waldron, V. R., Goman, C., Piemonte, N., Kloeber, D. \& Danaher, J. (November, 2012). How parents communicate right and wrong: A study of moral messages recalled by emerging adults. Unpublished paper presented at The National Communication Association Annual Meeting, Orlando, FL.

Wang, T. R. (2012). Understanding the memorable messages first-generation college students receive from on-campus mentors. Communication Education, 61(4), 335-357.

Woman play sports but not on TV. (2011). Retrieved from http://www.womenssportsfoundation.org/home/research/articles-andreports/media-issues/women-play-sports-but-not-on-tv

Wood, J. T. (2011). Gendered lives: Communication, gender, and culture $\left(9^{\text {th }}\right.$ ed.). Boston, MA: Cengage Learning. 
APPENDICES 


\section{APPENDIX A}

\section{COMMUNICATION QUESTIONNAIRE}

General Instructions: This study is being conducted by University of Akron graduate student Shawn C. Starcher for his master's thesis. For this study, I am interested in any messages or stories you remember your father or step-father sharing with you regarding sports that have had a lasting impression on you. In other words, I am interested in knowing about any messages you can recall your father sharing with you while watching, participating or talking about sports that have stuck with you. For example, your father may have told you to "always give 100\%" when playing sports or "win at any costs." These types of messages typically would have stayed with you and affected the way you think, feel or act in any setting, even outside of sports. It doesn't mean that you took your father's advice, I am simply interested in the messages you remember hearing and how you thought and felt about the message.

The questionnaire should take approximately 10-15 minutes to complete. Your participation is voluntary and there is no penalty for non-participation. Furthermore, you may withdraw from the study at any time without penalty. There is very little, if any, risk associated with participating in this study. Your responses will remain confidential and your identity will not be revealed. You must be at least 18 years old to participate in this study.

Please complete this questionnaire as honestly and thoroughly as possible. I am available to answer any questions if you should have them at the following e-mail address:

sshawn@zips.uakron.edu 
1. What is your age? Years

2. What is your sex? Male Female

3. What is your ethnic background/race?

African American/Non-Hispanic

Caucasian/Non-Hispanic

Hispanic

Asian/Pacific Islander

American Indian/Alaskan Native

Other (Please specify:

4. Did you play sport(s) as a child or adolescent (i.e. city leagues, middle school, high school, travel teams, etc.)? Yes No

5. If you did play sport(s) as a child or adolescent, which sport(s) did you play?

6. Are you currently playing any sport(s) now? Yes No

7. If you are playing any sport(s) now, which sport(s) are you currently playing?

8. Did you have a father or step-father in your life while growing up? Yes__ No (Skip to end if response is no)

9. Did you talk about sports with your father when you were growing up? Yes No

10. Do you talk about sports with your father today? Yes No

11. If you don't talk about sports with your father today, why not?

12. How important is/was talking about sports to your relationship with your father?

$\begin{array}{lllllllll}\text { Not Important } 1 & 2 & 3 & 4 & 5 & 6 & 7 & \text { Important }\end{array}$


13. Why is/was talking with your father about sports important or not important?

14. Who did you talk about sports or watch sports with the most with while growing up? (Circle best answer)

Father MotherBrother(s) Sister(s) Other

15. Do you have any children? Yes _ No If so, how many What are their sexes and ages? (Check the appropriate response(s))
a. Male Female Age
b. Male Female
c. Male Female Age
d. Male Female Age Age

\section{$\underline{\text { Memorable Messages }}$}

On the pages that follow, please list any messages that you recall your father or stepfather sharing with you while watching/listening to sports, playing sports or talking about sports together and answer the questions that follow.

Examples of memorable messages might be something like:

- "My father used to always tell me to give $100 \%$ all the time."

- "My father used to tell me that if you aren't cheating, then you aren't trying!"

- "My father used to tell me that I needed to be a good sport win or lose."

- "My father used to tell me that winning is all that matters, even if I have to cheat in order to win."

These examples should not limit the responses you share as they are simply meant as a guide to prompt your own memory about these experiences. Please only list the 2 most important messages that you can recall. Please include as much detail as possible. Think about what your father or step-father said to you and what the message meant to you. For each message that you recall, please answer the questions that follow. 


\section{Memorable Message 1:}

16. How old were you when this message was first received (circle the appropriate age range)?
Under age 5
$5-8$
$9-12$
$13-18$
19-older

17. Why do you think your father shared this message with you? (Please explain and be as specific as possible)

18. If you have/had/or plan to have a child, would you or did you pass along this message or story on to them?
Never
23

3
4
$\begin{array}{lll}6 & 7 & \text { Always }\end{array}$

19. Why would or wouldn't you pass this message along to your child?

20. If you would not share this message with your own child, what memorable message would you share with your child? Please explain and be as specific as possible. 


\section{Memorable Message 2:}

21. How old were you when this message was first received (circle the appropriate age range)?
Under age 5
$5-8$
$9-12$
$13-18$
19-older

22. Why do you think your father shared this message with you? (Please explain and be as specific as possible)

23. If you have/had/or plan to have a child, would you or did you pass along this message or story on to them?

$\begin{array}{lllllllll}\text { Never } & 1 & 2 & 3 & 4 & 5 & 6 & 7 & \text { Always }\end{array}$

24. Why would or wouldn't you pass this message along to your child?

25. If you would not share this message with your own child, what memorable message would you share with your child? Please explain and be as specific as possible. 
Please answer the following questions regarding your father or step-father. If your father or step-father is no longer alive or in your life, please answer the questions based on your relationship when he was present in your life.

For items 28 through 32, use the following scale:

$$
\begin{gathered}
\text { Very strong disagreement }=1 \\
\text { Moderate disagreement }=2 \\
\text { Slight disagreement }=3 \\
\text { Neutral }=4 \\
\text { Slight agreement }=5 \\
\text { Moderate agreement }=6 \\
\text { Very strong agreement }=7
\end{gathered}
$$

26. My father and I have/had a good relationship

27. My relationship with my father is/was very stable

28. My relationship with my father is/was strong

29. My relationship with my father makes/made me happy

30. I really feel/felt like part of a team with my father

31. On a scale of 1-10 ( $1=$ Very unhappy and $10=$ Perfectly happy), what is/was your degree of happiness, everything considered, in your relationship with your father?

Thank you for your assistance in this research study. Your participation is greatly appreciated!

Please contact Shawn Starcher at sshawn@zips.uakron.edu if you would like to learn more about this project or contact the University of Akron IRB (330-972-7666) if you have any concerns about this project. 
APPENDIX B

\section{CONTENT ANALYSIS CODEBOOK}

\begin{tabular}{|c|c|c|c|}
\hline & Supra-Type Categories & Main Idea of Message & Key words/phrases \\
\hline \multirow[t]{5}{*}{1} & Effort & $\begin{array}{l}\text { The parents were conveying the idea for the child to } \\
\text { never give up and maximize their effort in order to } \\
\text { achieve their maximum potential on the practice field } \\
\text { or during games. }\end{array}$ & \\
\hline & Subtype: Try your best & & $\begin{array}{l}\text { try your best, do your best, work } \\
\text { hard, hard work }\end{array}$ \\
\hline & Subtype: Never give up & & $\begin{array}{l}\text { never quit, never over, finish, stick } \\
\text { with it }\end{array}$ \\
\hline & Subtype: Give $100 \%$ & & give $100 \%$, give it your all \\
\hline & Subtype: Practice is important & & $\begin{array}{l}\text { practice to be good, practice makes } \\
\text { perfect }\end{array}$ \\
\hline \multirow[t]{4}{*}{2} & Quality Traits & $\begin{array}{l}\text { The parents were conveying the idea for the child to not } \\
\text { cheat, play by the rules, show good sportsmanship and } \\
\text { remain loyal at all times. }\end{array}$ & \\
\hline & Subtype: Good sport & & $\begin{array}{l}\text { gracious, good sport, } \\
\text { sportsmanship, respect rules, honor, } \\
\text { never fight, integrity, act like you } \\
\text { should, leadership }\end{array}$ \\
\hline & Subtype: No cheating & & don't cheat, play fair \\
\hline & Subtype: Loyalty to others & & $\begin{array}{l}\text { home team, support your teammates, } \\
\text { loyal, being there, loyalty, family }\end{array}$ \\
\hline \multirow[t]{3}{*}{3} & Emphasis on physical skills/performance & $\begin{array}{l}\text { The parents were offering tips for the child to improve } \\
\text { their physical skills and technique or commenting on } \\
\text { their child's lack of skills, while also emphasizing that } \\
\text { winning should be the ultimate goal at all times. }\end{array}$ & \\
\hline & Subtype: Physical skills & & $\begin{array}{l}\text { improve skills, technique, sports } \\
\text { isn't for everyone, mentioning of } \\
\text { body parts for improving skills }\end{array}$ \\
\hline & Subtype: Winning/performance is everything & & $\begin{array}{l}\text { win at any cost, do well or else, not } \\
\text { winning then you're losing, winning } \\
\text { is everything, play to win }\end{array}$ \\
\hline \multirow[t]{3}{*}{4} & Attention on others & $\begin{array}{l}\text { The parents were emphasizing the value of others } \\
\text { outside of the child directly. The fathers typically } \\
\text { focused on some aspect of professional athletes in } \\
\text { regards to their skill, value or conduct off the field or } \\
\text { that the team is more important than the individual. }\end{array}$ & \\
\hline & Subtype: Professional athletes & & $\begin{array}{l}\text { not heroes, professional athletes, } \\
\text { professional players }\end{array}$ \\
\hline & Subtype: Importance of team & & $\begin{array}{l}\text { no "I" in team, every position is } \\
\text { important, team more important }\end{array}$ \\
\hline 5 & Have fun & $\begin{array}{l}\text { The parents were conveying the idea for the child to } \\
\text { have fun first and foremost. }\end{array}$ & $\begin{array}{l}\text { have fun, enjoy yourself, joy, fun, not } \\
\text { always about winning }\end{array}$ \\
\hline
\end{tabular}




\section{APPENDIX C}

\section{UNIVERSITY OF AKRON IRB APPROVAL}

Office of Research Administration

Akron, $\mathrm{OH} 44325-2102$

NOTICE OF APPROVAL

April 22, 2013

Shawn Starcher

5416 Villarose Avenue NW

Massillon, Ohio 44647

From: Sharon McWhorter, IRB Administrator 4 (

Re: IRB Number 20130409 "Memorable Messages from Fathers to Children through Sports: Perspectives from Sons and Daughters"

Thank you for submitting your IRB Application for Review of Research Involving Human Subjects

for the referenced project. Your application was approved on April 22, 2013. Your protocol represents minimal risk to subjects and matches the following federal category for exemption:

$\square$ Exemption 1 - Research conducted in established or commonly accepted educational settings, involving normal educational practices.

Exemption 2 - Research involving the use of educational tests, survey procedures, interview procedures, or observation of public behavior.

$\square$ Exemption 3 - Research involving the use of educational tests, survey procedures, interview procedures, or observation of public behavior not exempt under category 2 , but subjects are elected or appointed public officials or candidates for public office.

$\square$ Exemption 4 - Research involving the collection or study of existing data, documents, records, pathological specimens, or diagnostic specimens.

$\square$ Exemption 5 - Research and demonstration projects conducted by or subject to the approval of department or agency heads, and which are designed to study, evaluate, or otherwise examine public programs or benefits.

$\square$ Exemption 6 - Taste and food quality evaluation and consumer acceptance studies.

Annual continuation applications are not required for exempt projects. If you make changes to the study's design or procedures that increase the risk to subjects or include activities that do not fall within the approved exemption category, please contact me to discuss whether or not a new application must be submitted. Any such changes or modifications must be reviewed and approved by the IRB prior to implementation.

Please retain this letter for your files. This office will hold your exemption application for a period of three years from the approval date. If you wish to continue this protocol beyond this period, you will need to submit another Exemption Request. If the research is being conducted for a master's thesis or doctoral dissertation, the student must file a copy of this letter with the thesis or dissertation.

Cc: E. Graham - Advisor

$\square$ Approved consent form/s enclosed

CC: Valerie Callanan - IRB Chair 